\title{
PENANGANAN KARGO INCOMING DALAM MENUNJANG KELANCARAN PENGIRIMAN BARANG (TINJAUAN EMPAT ASPEK)
}

\author{
*Muhamad Miftahul Achir ${ }^{1}$, Ryan Firdiansyah Suryawan², Evaf Maulina ${ }^{3}$, Hendy Tannady ${ }^{4}$ \\ 1,2,3 Sekolah Tinggi Penerbangan Aviasi, Jakarta Barat, DKI, Jakarta \\ ${ }^{4}$ Institut Teknologi dan Bisnis Kalbis, Jakarta, Indonesia \\ *Email Korespondensi: \\ ryan.firdiansyah.1979@gmail.com
}

\section{ARTIKEL INFORMASI}

Diterima:

25 Desember 2021

Direvisi:

12 Januari 2022

Dipublikasi:

30 Januari 2022

\begin{abstract}
ABSTRAK
Metode penilitian yang yang digunakan dalam peneltian ini adalah kualitatif dekriptif dengan observasi di objek dari empat aspek yaitu sarana prasarana, tenaga kerja, prosedur kerja, dan pelaksanaan kegiatan, data deskriptif karena isi dalam penelitian ini memberikan gambaran dan memaparkan objek penelitian berdasarkan kenyataan yang ada secara kronologis dan sistematis berdasarkan permasalahan yang terkait degan memaksimalkan pengumpulan data yang dilakukan menurut dokumen, wawancara, dan observasi. Hasil penelitian menunjukkan ditinjau dari empat aspek berjalan dari hasil observasi, hasil ini sebagai gambaran mengenai proses penanganan kargo incoming dalam menunjang kelancaran pengiriman barang dengan objek di salah satu maskapai di Indonesia.
\end{abstract}

Kata Kunci: Penanganan Kargo Incoming, Pengiriman Barang

\section{PENDAHULUAN}

Pengiriman barang menggunakan transportasi udara sangat menjaga keamanan barang, karena keamanan sebagai utama dalam menjaga kepercayaan pelanggan untuk tetap menggunakan pesawat udara dalam pengiriman barang. Oleh karena itu, kegiatan pelayanan terhadap muatan / barang masuk yang melalui bandar udara, meliputi unloading, pemindahan dari pesawat udara ketempat penyimpanan (gudang kargo), penyusun dan penyimpan barang tersebut serta menyerahkan kepada pemiliknya, harus sampai ketujuan dengan aman dan barangpun dalam keadaan semestinya. Loading and Unloading merupakan kegiatan yang dilakukan di apron area yaitu kegiatan bongkar muat barang (bagasi, kargo dan mail) dari dan dalam pesawat. Loading, dilakukan pada saat pre fight artinya kegiatan memuat barang (bagasi, kargo dan mail) dilakukan sebelum pesawat melakukan penerbangan oleh petugas-petugas ground handling. Adapun kegiatan unloading biasanya dilakukan pada saat post fight, artinya kegiatan bongkar barang dilakukan setelah pesawat melakukan penerbangan. Untuk menjaga kualitas dan kepercayaan pelanggan, maka maskapai harus mencegah terjadinya kesalahan-kesalahan / irregularities penanganan kargo yang dating ke unit incoming pergudangan, seperti damage cargo (kargo hilang) 
yang dapat mempengaruhi kualitas pelayanan yang diberikan oleh maskapai. Kesalahan-kesalahan ini dapat berdampak pada menurunnya tingkat kepercayaan (negative image) dari pelanggan. Kerusakan kargo bisa terjadi pada proses perpindahan barang yang tidak pada tempatnya dan kurangnya pemahaman petugas serta kurangnya tanggung jawab dalam bekerja.

Dalam pelayanan kargo tersebut, tidak jarang pula terjadi kesalahan-kesalahan/irregularities dalam penanganannya, yang akan mempengaruhi kualitas pelayanan. Kesalahan-kesalahan (irregularities) dan kendala yang terjadi bisa di sebabkan oleh faktor internal maupun eksternal. Faktor internal meliputi SDM, citra perusahaan, pelayanan, fasilitas, metode yakni pengontrolan packaging kurang maksimal, proses unloading storage. Faktor eksternal bisa meliputi kebutuhan masyarakat, harga, loyalitas konsumen antar lain bermunculan pesaing, cuaca daya saing harga, pajak yang tinggi, kesalahan build up dari bandara origin, kesalahan tata letak di pesawat penyebab lainnya. Dikaitkan dengan sarana prasarana di maskapai yang dilakukan observasi ini dalam proses kargo incoming, tenaga kerja yang mendukung dalam proses penanganan kargo incoming, prosedur kerja yang ada di maskapai dalam penanganan kargo incoming serta pelaksanaan kegiatan yang sudah disebutkan di atas seperti faktor internal dan eksternal. Semua ini adalah fenomena dan gambaran yang akan ditampilkan dalam artikel ini.

\section{KAJIAN PUSTAKA}

Kargo didefinisikan secara sederhana adalah semua (goods) atau barang yang dikirim melalui udara (pesawat terbang ), laut (kapal), atau darat (truk container) yang biasanya untuk diperdagangkan, baik baik wilayah atau kota di dalam negeri maupun internasional yang dikenal dengan istilah ekspor- impor (warpani, 2009-95). Kargo melalui udara adalah barang yang dikirim tanpa disertai oleh penumpang, pengiriman bisa melalui maskapai penerbangan ataupun agen kargo (freight forwarder). freight forwarder adalah seseorang ataupun suatu badan hokum yang melaksanakan perintah pengiriman barang (muatan/kargo) dari satu atau beberapa pemilik barang, yang dikumpulkan dari suatu tempat atau beberapa tempat, sampai ketujuan akhir yaitu penerima barang dengan melalui system pengaturan lalu lintas barang dan dokumen, dengan menggunakan satu atau beberapa moda transportasi tanpa harus memiliki sarana angkutan sendiri. Forwarder adalah tempat dimana para pemilik barang akan menerima sebagai macam advise/nasehat darinya tentang segala sesuatu mengenai aspek-aspek dalam pengiriman dan pengangkutan barang.

Kargo dibagi ke dalam dua golongan besar, yaitu general cargo dan special cargo.

a. General Cargo, General Cargo adalah barang-barang kiriman biasa sehingga tidak perlu memerlukan penanganan sacara khusus, namun tetap harus memenuhi persyaratan yang ditetapkan dan aspek safety.

b. Special Cargo, Special cargo adalah barang-barang kiriman yang memerlukan penanganan khusus (special handling). Jenis barang pada dasarnya dapat diangkut lewat angkutan udara dan harus memenuhi persyaratan dan penanganan secara khusus sesuai dengan regulasi IATA dan atau pengangkut, bahan benda yang termasuk dalam kategori special cargo adalah :

c. Live Animal (AVI), Adalah hewan-hewan hidup yang dikirim melalui pesawat udara seperti anak ayam, kuda, kambing ikan, dan lain-lain.

d. Perishable Goods (PER), Adalah barang-barang yang mudah sekali rusak, hancur, atau busuk, seperti buah-buahan, sayuran, daging, bunga, ikan dan bibit tanaman. Sehingga dalam pemuatannya harus ada bahan pengawet atau pendingin suhu udara agar tahan lama dalam perjalanan/pengiriman. Parishable Goods memerlukan perhatian khusus dalam penerimaan dan pengiriman sehingga tiba di tempat tujuan agar keadaan barang tidak rusak dan masih segar.

e. Human Remain (HUM), Adalah mayat manusia, yang di bagi menjadi dua yaitu :

1) Uncremated in Coffin adalah mayat yang masih berbentuk jasad yang di angkut dengan menggunakan peti jenazah.

2) Cremated yaitu jenazah yang sudah berupa abu (ashes) dan biasanya di kirim Dengan menggunakan kotak guci atau kotak kayu.

f. Valuable Goods (VAL) Adalah merupakan barang-barang yang memiliki nilai yang tinggi atau barangbarang berharga seperti emas, intan, berlian, cek, platina, dan lain-lain.

g. Live Human Organ ( $\mathrm{LHO}$ ), Adalah barang-barang yang berupa organ tubuh manusia yang masih berfungsi seperti bola mata, ginjal, hati.

h. Strongly Smelling Goods, Yaitu barang yang memiliki bau yang sangat menyengat seperti durian, minyak wangi, minyak kayu. 
i. Dangerous Goods $(D G)$, adalah barang-barang yang berbahaya atau dapat mengakibatkan terganggunya kesehatan, dan keselamatan penerbangan. Contohnya seperti :

1) Explosive Material, dengan zat kode REC. Barang ini mudah meledak, karena mengandung zat-zat kimia yang mudah meledak. Contoh: adalah amunisi, petasan, dan lain-lain.

2) Non Flammable Compressed Gas(RNG),contoh:film

3) Irritab Material. Barang atau bahan yang mengandung zat perangsang atau dapat merangsang bendabenda lainnya, seperti alcohol, gas dan spiritus.

4) CarrosiveMaterial( $R C M)$. Barang ini dapat menimbulkan karat. Contoh: air raksa dan zat asam.

5) FlammableGoods. Barang ini mudah terbakar baik dalam bentuk gas (RFG), padat (RFS) maupun dalam bentuk cair (RFL). Contoh: oxygent.

6) Magnetized Material (MAG). Barang yang mengandung unsur magnet. Contoh:kompas, loudspeaker, dan lain-lain.

7) Oxidizing Material. Barang yang mudah terbakar bila bereaksi dengan O2. Contoh: zat pemutih, nitrat, peroksida.

8) Fragile Goods (FRG). Barang-barang yang mudah pecah-belah. Contoh: barang terbuat dari porselen, kaca gelas, dan lain-lain.

9) Poisonous Substances (RPS).Barang - barang yang berupa racun, pengangkutannya harus ada izin dari pihak berwenang. Contoh: cianida, arsenik, dan lain-lain.

10) Radio Active Material. Bahan-bahan yang mengandung radioaktif.

11) Wet freight. Golongan barang-barang yang berbentuk cairan atau barang padat yang bercampur dengan cairan sehingga pemuatannya harus di dalam kontainer. Contoh: daging segar, udang basah, telur, dll.

Impor adalah proses pembelian barang atau jasa asing dari suatu negara ke negara lain. Impor barang secara besar umumnya membutuhkan campur tangan dari bea cukai di negara pengirim maupun penerima. Impor adalah bagian penting dari perdagangan internasional. Jika perusahaan menjual produknya secara lokal, mereka dapat menfaat karena harga lebih murah dan kualitas lebih tinggi dibandingkan pasokan dari dalam negeri. Impor sangat dipengaruhi 2 faktor yakni, pajak dan kuota. Tingkat impor dipengaruhi oleh hambatan peraturan perdagangan. Pemerintah mengenakan tarif (pajak) pada produk impor. Pajak itu biasanya dibayar langsung oleh importer, yang kemudian akan membebankan kepada konsumen berupa harga lebih tinggi dari produknya. Demikianlah sebuah produk mungkin berharga terlalu tinggi dibandingkan produk yang berasal dari dalam negeri. Ketika pemerintah asing menerapkan tarif, kemampuan perusahaan asing untuk bersaing di Negaranegara itu dibatasi. Pemerintah juga dapat menerapkan kuota pada produk impor, yang membatasi jumlah produk yang dapat diimpor. Jenis hambatan perdagangan seperti ini bahkan lebih membatasi dibandingkan tarif, karena secara eskpilit menetapkan batas jumlah yang dapat diimpor. (ryan firdiansyah suryawan, primadi candra susanto, 2020).

Cargo Handling adalah kegiatan pelayanan terhadap muatan / barang (keluar dan masuk) yang melalui Bandar udara, meliputi loading unloading, pemindahan dari pesawat udara ketempat penyimpanan (gudang kargo), menyusun dan menyimpan barang tersebutserta menyerahkan kepada pemiliknya, atau sebaliknya menerima dari si pemilik, disususn di dalam tempat penyimpanan (gudang kargo), dipindahkan dari tempat penyimpanan kepesawat udara dan memuat serta menyusun di dalam ruangan comparment pesawat udara, dengan pengertian bahwa dengan melaksanakan semua kegiatan tersebut dengan pengetahuan serta keahlian. (Suharto Abdul Madjid, Eko Probo Warpani, 2009). Cargo Service itu merupakan layanan khusus angkutan barang-barang dengan mempergunakan pesawat udara angkutan khusus untuk barang. Service / pelayanan ini bisa di selenggarakan oleh suatu perusahaan penerbangan reguler yang melayani penumpang, tetapi dapat pula oleh suatu perusahaan khusus angkutan barang (Khodayat \& Ramaini, 1997:17).

Incoming yaitu proses penerimaan barang yang dimulai dari kegiatan loading unloading atau bongkar muat barang sampai barang tersebut diterima dari pihak penerima. Dokumen pendukung dalam penanganan dan pelayanan kargo incoming dapat diketahui dalam beberapa hal :

1) ManifestCargoInbound

2) SMU(SuratMuatanBarang)

3) SRT(SuratKarantinauntukLiveAnimal)

4) BukuTransit

Persiapan Incoming Cargo

1) Persiapan 
a) Briefing, cek logbook \& particular

b) Cek schedule ETA, Parking Stand \& Type Pesawat

c) Cek msg / telek yang masuk / irregularities

d) Cek keadaan gudang dan peralatan pendukung yang lain dalam kondisi yang baik.

e) Cek / menyiapkan formulir-formulir :

1) Cargo demage / lost report

2) Cargo tracing ( tracer ) report

3) Pemberitahuan kedatangan barang

4) Cargo irregularity report

2) Pelaksanaan

a) Mengambil Flt-bag cargo dari pesawat

b) Memeriksa cargo manifest, bila ada hal-hal yang perlu mendapatkan perhatian segera (barang kiriman khusus, trasit )

c) Mengawasi barang kiriman dari pesawat sampai gudang

d) Cek dokumen ( SMU / AWB, AV-7, Cargo Manifest )

Pergudangan, menurut Noerhayanto ( $2000: 4$ ) adalah suatu kegiatan pengurusan barang yang meliputi, menerima barang, menyimpan barang sesuai persyaratannya, memelihara barang, memelihara kebersihan ruang tempat penyimpanan barang mengeluarkan barang sesuai dengan keperluan, mengurus administrasinya, dan mempertanggung jawabkan pengurusan tersebut, berdasarkan lokasi pelayanannya, gudang terbagi menjadi dua lini yaitu :

1) Gudang Lini I, Gudang tempat penyimpanan barang baik yang baru diturunkan atau untuk sementara menunggu barang diangkut ke kapal laut atau pesawat udara, dipindahkan ketempat lain setelah dipriksa oleh pihak pebean.

2) GudangLiniII

Gudang ini hanya digunakan untuk ruang penyimpanan dan penumpukan barang, selama barang-barang itu diproses dokumennya sampai selesai, tetapi masih dalam pengawasan pihak pabean.

\section{METODE}

Metode penelitian yang digunakan adalah deskriptif kualitatif kualitatif dekriptif dengan observasi di objek dari empat aspek yaitu sarana prasarana, tenaga kerja, prosedur kerja, dan pelaksanaan kegiatan, melalui observasi terbatas pada perusahaan penerbangan skala nasional, wawancara terbatas menyangkut empat aspek di atas dan studi literatur guna mendukung dengan refrensi yang tersedia.

\section{HASIL DAN PEMBAHASAN}

Adapun hasil pembahasan dilihat dari empat aspek hasil dari observasi lapangan, wawancara dengan karyawan perusahaan penerbangan didapatkan hasil sebagai berikut ;

a. Sarana dan Prasana mendapatkan jawaban sangat mendukung untuk melakukan proses kinerja penanganan barang kargo yang diterima. Kondisi sarana yang tersedia di PT Garuda Indonesia keseluruhan baik dan dapat berfungsi optimal, sehingga para karyawan dapat bekerja secara optimal dalam menangani barang kargo yang diterima, prasarana yang tersedia ada prasarana yang kurang baik dan kurang layak untuk digunakan, sehingga mengganggu kinerja dalam menangani barang-barang kargo, namun dikarenakan sedang adanya renovasi gedung.

b. Tenaga Kerja, sesuai hasil pengamanatan atau observasi bahwa karyawan maskapai dalam menjalankan tugas menggunakan seragam, dalam bagian penanganan kargo ada sebelas karyawan memiliki lisensi dan pengalaman, selain itu ada karyawan yang ditugaskan sebagai kasir, aviation security, supervisor, Koordinator penanganan kargo, staf yang menangani dokumen, serta jam kerja dilaksanakan oleh karyawan.

c. Prosedur kerja, Karyawan kargo melaksanakan prosedur kerja cargo incoming dengan berkordinasi kepada pihak-pihak terkait. Adapun prosedur penerimaan dan penyimpanan barang yang datang, Prosedur penerimaan barang kargo Incoming 
1. Petugas warehouse menerima dokumen SMU (Surat Muatan barang) dan manifest cargo dari crew cabin.

2. Momonitor unloading atau bongkar muat barang

3. Memonitor penarikan gerobak isi kargo ke warehouse lini I atau gudang

4. Pendataan kargo yang masuk ke gudang dari pesawat (jumlah koli, jumlah berat, nomor SMU, kondisi atau keadaan kargo, penerima kargo)

5. Membuat bukti tanda terima kargo yang ditandatangani oleh petugas warehouse dengan consignee (penerima)

6. Bila ada kargo yang rusak atau kurang, petugas segera membuat irregulity report dan melakukan penelusuran ke kota asal pengirim kargo.

7. Copy irregulity report untuk dilaporkan kepada bagian yang menangani masalah

Prosedur pengambilan barang pengambilan barang oleh consignee di gudang incoming.

1. Consignee, Membawa SMU, ID-Card, Surat kuasa untuk orang yang di suruh

2. Docpross, Menerbitkan bukti terima barang

3. Consignee, Membayar jasa Gudang

4. Checker, Mengeluarkan barang dari Gudang

5. Consignee, Menerima barang

6. Start, Petugas docpross meminta No SMU untuk proses dalam pengambilan bukan pemilik barang tersebut agar sesuai barang yang akan di ambil.

7. Consignee, Memberikan No SMU atau surat kuasa bila yang mengambil bukan pemilik barang tersebut agar tidak terjadi kesalahpahaman dalam mengambil barang tersebut.

8. Cashier, Petugas cashier menerbitkan receipt berupa jumlah berat dan jumlah koli barang yang masuk kedalam gudang dan menghiting jumlah tarif sewa yang harus dibayar oleh consignee

9. Consignee, Membayar biaya sewa gudang sesuai dengan receipt pembayaran yang dikeluarkan maskapai

10. Checker incoming, Mengeluarkan barang sesuai dengan SMU yang diberikan oleh Document Processing untuk diberikan kepada consignee

11. Consignee, Menerima barang dan memasukan barang kedalam kendaraan dengan dibantu oleh porter.

Dalam penjabaran prosedur sudah tergambarkan mengenai penanganan incoming penanganan kargo handling, karyawan bisa menjalankan sesuai observasi, pihak luar juga sebagai pengguna jasa.

d. Pelaksanaan Kegiatan, Pelaksanaan yang dilakukan oleh Maskapai dalam mengenai barang kargo pada unit incoming sudah dilaksanakan dan sudah sesuai dengan prosedur yang berlaku, hal ini sangat mendukung kinerja (pengamatan dan data jadi) dari pergudangan untuk memberikan pelayanan optimal dan memuaskan konsumen. Kendala atau penyebab terhambatnya cargo incoming di gudang sebagai berikut :

1. Delay yang disebabkan pesawat mengalami kerusakan, cuaca ekstrim.

2. Peak season yaitu masa puncak atau masa ramai dari kiriman cargo domestic umumnya adalah masa menjelang hari raya tersebut.

\section{KESIMPULAN DAN SARAN}

Proses cargo handling ialah Loading unloading atau bongkar muat barang, Barang diterima consignee pihak penerima, Cargo handling merupakan pekerjaan keahlian dan ketelitian yang tinggi dalam setiap pengerjaannya. Agar tercipta penanganan kargo para karyawan harus diimbangi dengan pengetahuan atas pekerjaannya yang baik dan sangat mendukung untuk menunjang kinerja dalam menangani barang kargo yang diterima melalui pergudangan, Serta tenaga kerja yang cukup ahli dan berpengalaman dibidangnya, maka Maskapai dapat bekerja secara baik untuk menjaga meningkatkan kualitas pelayanannya. Keselamatan dan keamanan barang yang datang merupakan hal yang harus diperhatikan oleh karyawan secara baik, terutama dalam hal penerimaan barang, oleh karena itu semua karyawan harus memiliki pengetahuan dalam hal penanganan cargo. Agar proses penerimaan barang 
sacara terlaksana dengan baik dan benar sesuai prosedur yang berlaku. Prosedur kerja dalam menangani barang kargo yang diterima melalui pergudangan dan dapat mendukung mendukung kegiatan dalam proses penanganan penerimaan barang dapat berjalan dengan baik dan lancar.

Proses pelaksanaan kegiatan yang dilakukan PT Garuda Indonesia sudah cukup baik karena sudah memenuhi standar operasinal prosedur yang mengacu pada peraturan-peraturan penerbangan yang berlaku. Dengan demikian kinerja yang dihasilkan oleh PT Garuda Indonesia dapat berjalan sebagaimana mana mestinya tanpa ada hambatan yang dapat mengganggu jalannya kinerja.

\section{Daftar Pustaka}

Suharto A. Majid dan Eko Probo D. Warpani, 2009, Ground Handling : Manajemen Pelayanan Darat Perusahaan Penerbangan, STMT Trisakti Jakarta.

Azaura, Agustus 2016 Istilah dan Pengertian Loading Unloading. http://azaura.blogspot.com/2016/08/ini-diaistilah-dan-pengertian-dalam-html (diakses tanggal 15 Januari 2022)

Eyen, Lcc98, November 2012. Pengertian Cargo http://eyenlcc98.blogspot.com/2012/11/pengertiancargo.html?m=1 (diakses tanggal 20 Januari 2022)

Maritimes, World, Februari 2017. Apakah Freight Forwardind dan Forwarder http//maritimesworld.blogspot.com/2017/02/Apakah-Freight-Forwardind-dan-Forwarder.html?m=1, (diakses tanggal 20 Januari 2022)

Suryawan, ryan firdiansyah, dan susanto, primadi candra, 2020, pengantar kepabeanan, keimigrasian dan karantina edisi 3, Mitra Wacana Media.

Andrianto, Chandra, 25, November 2012. Ekspor dan Impor. http://andriantochandra25.wordpress.com/2012/11/01/pengertian-ekspor-dan-impor/ (diakses tanggal 15 Januari 2022) 